\title{
SORPTIVITY AND CHLORIDE PENETRABILITY EVALUATION OF CONCRETE INCORPORATING FLY ASH AND SILICA FUME
}

\author{
Wahyuniarsih Sutrisno ${ }^{a^{*}}$, Gabriel Ghewa ${ }^{\mathrm{b}}$, Priyo Suprobo ${ }^{\mathrm{a}}$
}

\begin{abstract}
Diffusion is one of the the main mechanisms of fluid ingress into the concrete. However, in partially saturated concrete, the fluid will mainly be absorbed by the capillary suction mechanism, which associates with the sorptivity properties of the concrete. This paper presents the results of an experimental program to investigate the influence of Portland cement substitution with Silica Fume (SF) and Type F Fly Ash (FA) on the rate of absorption, which also known as sorptivity, and chloride penetration of concrete. The sorptivity of the concrete was evaluated according to ASTM 1585, while the chloride penetration was evaluated according to ASTM C 1202. By substituting part of cement with FA and SF, it was found that the sorptivity of concrete is reduced. Furthermore, all type of concrete with supplementary material, including CFA, CSF and $C S M$, is confirmed to enhance the ability of concrete to resist chloride penetration compared yo normal concrete $(N C)$.
\end{abstract}

Keywords: Durability, Sorptivity, Chloride Penetrability, Fly Ash and Silica Fume

\section{INTRODUCTION}

In the recent decade, durability problems are becoming a concern to many engineer and researcher. Many constructions built in the 1900s and even the new poorly built structure is suffering to damage due to durability issues. Structures located in the area with the possibility of water intact, such as the marine environment, have a direct impact on the durability problems. In marine structure, the chloride ion is one of the main problems which can induce the corrosion problem [1]. In case corrosion induced by chloride, the passive layer of steel is damage due to chloride attack, and the corrosion process starts to develop [2], [3]. As the corrosion starts to develop, the volume of the rust will increase significantly and causing crack at the interface of the steel bar of concrete. Over time, the crack will see growth and reach the concrete surface. This condition will accelerate the chloride ingress and lead to faster development of corrosion. By looking at that fact, it is important to assess the concrete ability to resist chloride ion penetration to have a deep insight of chloride ion penetration into the concrete.

The significant problems of early deterioration in the concrete structures are occurring in structures that experience frequent environmental changes, such as cyclic drying and wetting [4]-[7]. As widely known, water and oxygen are the main factors that can induce the durability problems such as corrosion. Over a certain period of time, the frequent environmental changes will lead to the fluctuation of the effective diffusion coefficient. Therefore, considering diffusion alone in the service life modeling is not sufficient for most structures, and more research is needed to incorporate other mechanisms, especially sorptivity [4].

Sorptivity is a parameter which associates with the

${ }^{a}$ Lecturer in the Civil Engineering Department, Institut Teknologi Sepuluh Nopember, ITS Campus, Sukolilo, Surabaya 60111, Indonesia. Corresponding author email address: niar1206@gmail.com

${ }^{\mathrm{b}}$ Graduate Student in the Civil Engineering Department, Institu Teknologi Sepuluh Nopember, ITS Campus, Sukolilo, Surabaya 60111, Indonesia. rate of absorption of the concrete. When the concrete surface is not saturated at the specific time and it is exposed to a chloride solution, the capillary tension will absorb the water and chloride solution into the concrete. Over time, this condition will affect the pore structure of the concrete and causing durability problems. The pore structure mostly depending on the fluid penetration capacity of concrete which known as permeability [8]. Concrete with high permeability tends to absorb more water which leads to the introduction of molecules that react and destroy its chemical stability[9]. However, lower permeability of concrete can improve the durability performance of concrete by improving the penetration of water, chloride, sulfate, and other harmful substances [10]. Therefore, it is necessary to assess the fluid entrance rate into the concrete and one of the popular methods that can be used to assess this property of concrete is the rate of absorption or also known as sorptivity.

Besides frequent environmental changes, another factor that can affect the rate of diffusion and absorption of the concrete is the quality of the concrete material. Several researchers found that the raw material and quality of concrete material really affect the durability of concrete [11]-[13] including the rate of diffusion and absorption of the concrete. The concrete-based on Portland cement is the most widely used material in the world. Compared to other materials like steel, aluminum and plastics, it is the most viable option for the construction industry considering economic and environmental costs. However, the production of cement is very energy-intensive and releases a significant volume of $\mathrm{CO}_{2}$. To overcome this problem, many researchers used supplementary material to substitute the amount of cement used for concrete.

In recent years, fly ash, silica fume and blast furnace slag are the popular material for substituting cement or known as the supplementary material [10], [14]-[18]. Fly ash and silica fume are the waste product of the industrial processes. Fly ash is a by-product of coal-burning power plants and silica fume is produced by reducing the highpurity quartz with coal in electric arc furnaces in the manufactures of silicon and ferrosilicon alloys. The amount of this waste material is increasing rapidly every 
year. The chemical composition of Fly ash and silica fume which is rich in silica and Calcium Oxide, is believed to be able to increase the quality of concrete. Moreover, because fly ash and silica fume are classified as wastes, the utilization of these materials will be very influential in reducing waste and making eco-friendly concrete. In term of industrial application, fly ash is a popular supplementary material which has been used in the concrete industry for several years. ASTM classifies this material into two classes which are Class $\mathrm{C}$ and class F. Fly ash classified as Class F was a by- product of anthracite or bituminous coal and has pozzolanic properties [19] which makes this type of fly ash is very popular in the concrete industry. Moreover, the use of fly ash is also very popular because the chemical composition of FA is similar to cement which consists of silica ( $\mathrm{SiO} 2)$, lime $(\mathrm{CaO})$, alumina $\left(\mathrm{Al}_{2} \mathrm{O}_{3}\right)$, iron oxide $\left(\mathrm{Fe}_{2} \mathrm{O}_{3}\right)$, and magnesia (MgO) [17]. Similar to fly ash, the general chemical composition of silica fume also the same as Portland cement. Previous research shows that adding silica fume into the concrete can enhance the mechanical and durability properties of the concrete [14], [18], [20].

Therefore, an extensive experimental test to evaluate the sorptivity and chloride penetration of concrete incorporating Fly ash and Silica fume was presented in this research. In this research, four types of concrete, which are normal concrete (NC), concrete with $15 \%$ fly ash (CFA), concrete with 5\% Silica Fume (CSF) and Concrete with a combination of Fly Ash (10\%) and Silica Fume (5\%) (CSM), were used. The sorptivity of the concrete was evaluated by using the rate of absorption method [4]. Furthermore, the method presented in ASTM C 1202 was used to evaluate the chloride penetrability of the concrete.

\section{RESEARCH SIGNIFICANCE}

This paper discusses the effects of using fly ash, silica fume, and their combination as cement replacement. Most researchers used diffusion as the main mechanism of fluid ingress into the concrete. However, in partially saturated concrete, the fluid will mainly be absorbed by the capillary suction mechanism, which associates with the sorptivity of the concrete. Based on that fact, this research will evaluate the initial and secondary absorption rates (sorptivity) of the concrete with and without supplementary material i.e., fly ash and silica fume. In addition, an evaluation of chloride penetrability of the concrete will also be carried out to justify the relationship of sorptivity with chloride penetration and the effectiveness of using fly ash and silica fume to enhanced durability properties of concrete.

\section{METHODOLOGY}

For this research, type I of Portland cement, coarse aggregate, fine aggregate, fly ash, and silica fume were used to produce concrete mixtures. The chemical composition of Portland cement, fly ash, and silica fume is shown in Table 1. The concrete was design with water per cement ratio of 0.25 and a targeted compressive strength of $45 \mathrm{MPa}$. This research used three samples for each type of specimen. The mixture of concrete divided into four types, which are normal concrete (NC), concrete with fly ash (CFA), concrete with Silica Fume (CSF) and Concrete with the combination of Fly Ash and Silica Fume (CSM). CFA and CSF were made by substituting $15 \%$ and $5 \%$ of Portland cement with fly ash and Silica Fume, respectively. The CSM is made by combining fly ash and silica fume to substituting $15 \%$ cement.

Table 1. The Chemical Composition of OPC, Silica Fume, and Fly Ash

\begin{tabular}{cccc}
\hline Compound & OPC & FA & SF \\
\hline $\mathrm{Al}_{2} \mathrm{O}_{3}$ & 2.3 & 12.7 & 0.023 \\
$\mathrm{SiO}_{2}$ & 10.9 & 43.2 & 91.1 \\
$\mathrm{CaO}$ & 78.34 & 9.32 & 2.3 \\
$\mathrm{Fe} 2 \mathrm{O} 3$ & 4.77 & 26.6 & 1.37 \\
Other Compounds & 3.69 & & \\
\hline
\end{tabular}

The absorption test for this research was performed according to ASTM C1585 A concrete cylinder with a diameter of $100 \mathrm{~mm}$ and $200 \mathrm{~mm}$ height was used in this research. After 28 days of curing, the concrete sample was cut into $50 \mathrm{~mm}$ height before absorption, and all sides were wrapped with a plastic tape except the bottom side, which will act as the exposed surface. The weight of concrete was measured before and after sealing and it was used as an initial mass for calculating the absorption of concrete.

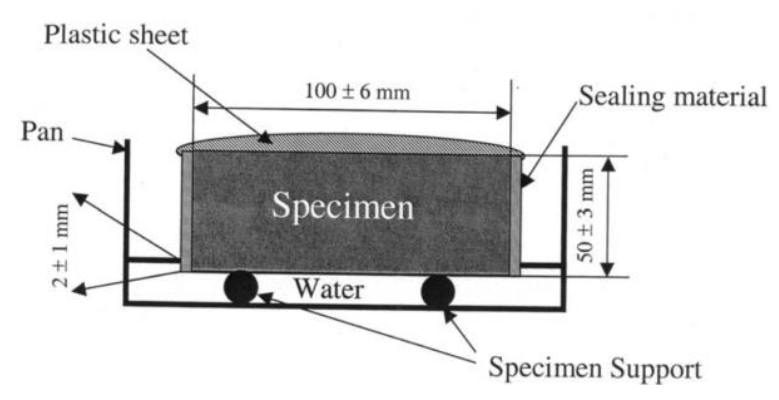

Figure 1. Test Set Up for Rate of Water Absorption Test (ASTM 1585) 


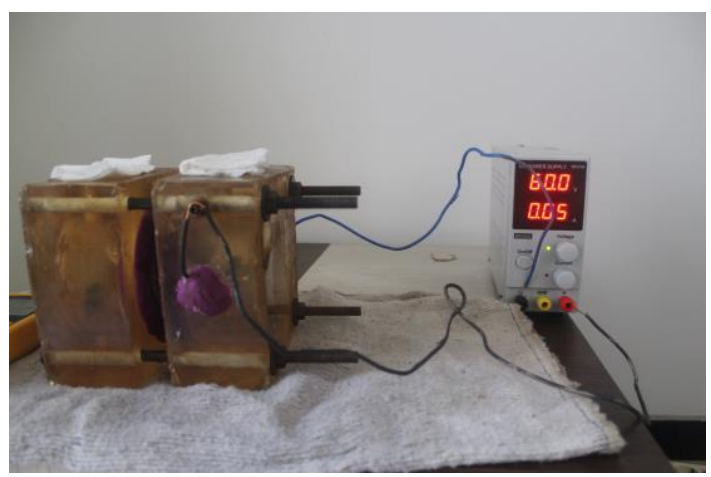

Figure 2. The RCPT Test Set Up

The sample was placed in the pan, which has been equipped with specimen support and tap water. The exposed surface of the specimen was submerged into the water. The water level is 1 to $3 \mathrm{~mm}$ above the top of the support device. The scheme of the test, according to ASTM C1585, was shown in Figure 1. The sample was weighed periodically, according to ASTM 1585. To weight the sample, it should be removed from the pan, and the stopwatch was simultaneously stopped. The excess water was removed by using a dry paper towel and quickly weighed. After the weighing process is finished, the sample was placed directly back into the pan. The accumulated water absorbed per unit area was plotted vs. the square root of time $(\sqrt{ } \mathrm{t})$ in minutes. The initial $(\mathrm{Si})$ and secondary (Ss) absorption were calculated by using linear regression and calculating the slope of the graph.

The Rapid Chloride Penetration (RCPT) Test was performed according to ASTM C 1202 by using the RCPT apparatus (see Figure 2). The sample used for this test is a concrete cylinder with a $100 \mathrm{~mm}$ diameter and 50 $\mathrm{mm}$ height. The test was performed after the concrete cured in 28 days. After curing, the concrete was removed from the curing water and excess water is removed by using a dry paper towel. In the next step, the concrete specimens undergo the vacuum process in the desiccator to remove all air particles. The specimen was then kept between RCPT's cell and all the gaps were sealed with silicone gel to prevent the leakage of the liquid. The anode cell was filled with $0.3 \mathrm{M}$ of Sodium hydroxide and the cathode cell was filled with a $3 \% \mathrm{NaCl}$ solution. A constant electric current of $60 \mathrm{~V}$ was applied into the specimen and the charge passed is recorded every 30minute intervals. The test set up for the rapid chloride penetration test is shown in Figure 2. The charge passed from the experimental test was compared with Table from ASTM C1202 which associated with Chloride ion penetrability. The compared Table from ASTM C1202 shown in Table 2.

Table 2. Ion Penetrability based on Charge Pass (ASTM 1202)

\begin{tabular}{cc}
\hline Charge Passed (Coulombs) & Chloride Ion Penetrability \\
\hline$>4000$ & High \\
$2000-4000$ & Moderate \\
$1000-2000$ & Low \\
$100-1000$ & Very Low \\
$<100$ & Negligible \\
\hline
\end{tabular}

\section{RESULT AND DISCUSSIONS}

The result of all experimental tests is presented in this section. The compressive strength test was performed to ensure the quality of concrete. The specimens used for the test are concrete cylinder with $10 \mathrm{~cm}$ diameter and 20 $\mathrm{cm}$ height. The result of the compressive strength test is shown in Table 3. All types of concrete were designed with the same water per cement ratio, and the targeted strength of concrete is $45 \mathrm{MPa}$. From the test result, it can be seen that adding fly ash and silica fume into the concrete resulting in considerable strength improvement compared with the control mixture (NC). Furthermore, the result also shows that at the age of 28 days, the CFA concrete has the highest average compressive stress compared with other types of concrete. Compared with $\mathrm{NC}$, the CSF has $7.48 \%$ higher compressive strength. This difference is higher compared with the differences between CSF and CSM compared to NC. The CSF and CSM concrete has $3.60 \%$ and $5.49 \%$ differences respectively compared to $\mathrm{NC}$.

Table 3. Average Compressive Test Result

\begin{tabular}{ccc}
\hline Type & w/c & $\begin{array}{c}\text { Average f'c } \\
\text { (Mpa) }\end{array}$ \\
\hline $\begin{array}{c}\text { Normal } \\
(\mathrm{NC})\end{array}$ & 0.25 & 47.177 \\
$\begin{array}{c}\text { FA 15\% } \\
(\mathrm{CFA})\end{array}$ & 0.25 & 50.703 \\
$\begin{array}{c}\text { SF 5\% } \\
(\mathrm{CSF})\end{array}$ & 0.25 & 48.873 \\
FA 10\%+ SF 5\% \\
$(\mathrm{CSM})$
\end{tabular}

The overall result of the compressive strength test shows that the addition of silica fume and fly ash into the concrete tends to increase its compressive strength. This condition happened because silica fume and fly ash contain high silicone dioxide, which really plays a great role in increasing the strength of the concrete. With the 
addition of supplementary materials, such as fly ash and silica fume, into the concrete, these materials will react with hydrated cement paste in a primarily pozzolanic reaction. This reaction will result in a denser microstructure of the concrete over time which leads to higher compressive strength.

The rate of absorption of the concrete was evaluated according to ASTM C 1585. The rate of absorption was observed by recording the incremental change of the mass of the concrete at frequent of the interval during the first six hours for initial absorption. While for secondary absorption, the rate was evaluated by frequently taking once a day measurement for the next 7 days. The change of the concrete mass over time was plotted, and linear regression was used to estimate the initial and secondary absorption. Table 4 shows the result of the rate of absorption test.

Table 4. Initial and Secondary Absorption Test Result

\begin{tabular}{cccccccccc}
\hline \multirow{2}{*}{ No } & $\begin{array}{c}\text { Sample } \\
\text { Code }\end{array}$ & \multicolumn{3}{c}{ Initial Absorption } & \multicolumn{4}{c}{ Secondary Absorption } \\
& Absorption $\left(\mathbf{m m} / \mathbf{s}^{\mathbf{1} / 2}\right)$ & $\mathbf{R}^{\mathbf{2}}$ & Intercept & Absorption $\left(\mathbf{m m} / \mathbf{s}^{\mathbf{1} / 2}\right)$ & $\mathbf{R}^{\mathbf{2}}$ & Intercept \\
\hline 1 & NC1 & 0.0188 & & 0.9852 & 0.6979 & 0.002 & & 0.9927 & 4.2892 \\
2 & NC2 & 0.0161 & 0.0185 & 0.9839 & 0.9782 & 0.002 & 0.0019 & 0.9899 & 3.9661 \\
3 & NC3 & 0.0206 & & 0.9831 & 1.0032 & 0.0016 & & 0.9965 & 4.4273 \\
4 & CFA1 & 0.0149 & & 0.9825 & 0.547 & 0.0014 & & 0.9899 & 3.4631 \\
5 & CFA2 & 0.0143 & 0.0134 & 0.9823 & 0.4968 & 0.0011 & 0.0012 & 0.9843 & 3.3095 \\
6 & CFA3 & 0.0109 & & 0.9863 & 0.3445 & 0.0011 & & 0.9899 & 2.2206 \\
7 & CSF1 & 0.0209 & & 0.9863 & 0.3445 & 0.0016 & & 0.9944 & 3.2448 \\
8 & CSF2 & 0.0155 & 0.0180 & 0.9822 & 1.0425 & 0.0017 & 0.0018 & 0.9818 & 4.3142 \\
9 & CSF3 & 0.0175 & & 0.9862 & 2.4439 & 0.0020 & & 0.9849 & 4.4858 \\
10 & CSM1 & 0.0170 & & 0.982 & 0.5459 & 0.0019 & & 0.986 & 3.115 \\
11 & CSM2 & 0.0195 & 0.0179 & 0.984 & 1.1099 & 0.0017 & 0.0017 & 0.9803 & 4.1206 \\
12 & CSM3 & 0.0171 & & 0.9888 & 1.0717 & 0.0016 & & 0.9873 & 3.5657 \\
\hline
\end{tabular}

Based on the result presented in Table 4, it can be seen that adding Fly Ash and Silica Fume into the concrete clearly decreases the value of initial and secondary absorption. The CFA concrete has the lowest initial and secondary water absorption compared with the other type of concrete. The rate of initial water absorption of CFA has $27.75 \%$ lower compared with normal concrete, while the CSF and CSM have $2.88 \%$ and $3.42 \%$ lower rate of absorption respectively, compared with normal concrete. In the case of secondary water absorption, the CFA presents an even better result with a $35.71 \%$ lower value compared with NC. While the CSF and CSM have $7.13 \%$ and $7.14 \%$ lower value of secondary absorption respectively compared with $\mathrm{NC}$, from this result, it can be concluded that concrete with $15 \%$ substitution of Fly Ash by cement mass has better performance against water compared with other types of concrete.

Table 5. The RCPT Result

\begin{tabular}{ccccc}
\hline Time & Normal & CFA & Recorded Current & CSF \\
\hline 0 & 0.05 & 0.05 & 0.05 & 0.05 \\
30 & 0.06 & 0.05 & 0.06 & 0.06 \\
60 & 0.06 & 0.06 & 0.06 & 0.07 \\
90 & 0.07 & 0.06 & 0.06 & 0.07 \\
120 & 0.08 & 0.06 & 0.07 & 0.07 \\
150 & 0.09 & 0.07 & 0.07 & 0.07 \\
180 & 0.09 & 0.07 & 0.07 & 0.07 \\
210 & 0.1 & 0.07 & 0.07 & 0.07 \\
240 & 0.11 & 0.08 & 0.07 & 0.07 \\
270 & 0.11 & 0.08 & 0.07 & 0.07 \\
300 & 0.12 & 0.08 & 0.08 & 0.07 \\
330 & 0.13 & 0.08 & 0.08 & 0.08 \\
360 & 0.14 & 0.09 & 0.09 & 0.09 \\
Calculated Charge Passed $(\mathbf{Q})$ & $\mathbf{2 1 3 3}$ & $\mathbf{1 5 7 5}$ & $\mathbf{1 5 7 5}$ & $\mathbf{1 5 9 3}$ \\
\hline
\end{tabular}


The substitution of cement with fly ash and silica fume in the concrete prove to increase the resistance of concrete against water. This condition happened due to particle characteristics of fly ash and silica fume. The particle of fly ash is relatively finer compared to Portland cement. Fly ash mainly entails of silt-sized particles with a spherical form with size ranging between 10 and 100 microns. Similar to fly ash, silica fume is also an ultrafine material with an average diameter of $0.15 \mu \mathrm{m}$ which approximately 100 times smaller compared with cement particle. Silica fume also has spherical particles like fly ash. These small particles of fly ash affect the composition of the pore structure of the concrete, which associated with its durability performance. Furthermore, the spherical form of both materials also improves the workability of fresh concrete.

The result of the rapid chloride penetration test, which performed according to ASTM 1202, presented in Table 5. The substitution part of cement with fly ash and silica fume in the concrete as cement replacement resulting substantial reduction on charge pass compared to normal concrete. The CFA and CSM concrete have a similar reduction of charge pass compared to normal concrete, while a CSF shows a slightly higher charge pass compared to CFA and CSM.

Evaluation of the charge pass value of each sample, according to ASTM 1202, is presented in Table 6. The result in Table 6 shows that adding fly ash and silica fume into the concrete significantly changes the chloride ion penetrability form moderate to low. The charge passed of the concrete in the RCPT test is dependent on the microstructure of concrete and chemical composition of the pore solution. As mentioned before, the fly ash and silica fume have a relatively small diameter compared with Portland cement. This condition produces improvement to the microstructure of the concrete. Furthermore, the chemical composition of the pore solution of the concrete, especially $(\mathrm{OH})^{-}$ion concentration, is really affecting the charged passed value. The use of supplementary material, such as fly ash and silica fume, affects the chemistry of pore solution by lowering the concentration of $(\mathrm{OH})^{-}$ion which associated with the improvement of the concrete ability against the chloride penetration. In this research, the addition of fly ash and silica fume into the concrete as the substitution of cement improved the chloride resistance in the range 25$26 \%$ compared with normal concrete.

Based on the sorptivity and chloride penetrability evaluation of four types of concrete, it can be seen that chloride penetrability has a similar trend with the sorptivity of the concrete. Concrete with supplementary materials tends to have lower sorptivity and chloride penetrability compared with ordinary concrete made from portland cement. This result is mainly due to the particle size of the fly ash and silica fume which tends to be smaller than portland cement. By adding smaller size materials into the concrete, the pore structure of the concrete is improved and leads to enhancement of its durability properties. Furthermore, adding this supplementary material also improved the overall strength of the concrete.
Table 6. Evaluation of chloride Ion Penetrability

\begin{tabular}{cccc}
\hline No & $\begin{array}{c}\text { Concrete } \\
\text { Type }\end{array}$ & $\begin{array}{c}\text { Charge } \\
\text { Pass }\end{array}$ & $\begin{array}{c}\text { Chloride Ion } \\
\text { Penetrability }\end{array}$ \\
\hline 1 & NC & 2113 & Moderate \\
2 & CFA & 1575 & Low \\
3 & CSF & 1575 & Low \\
4 & CSM & 1593 & Low \\
\hline
\end{tabular}

\section{CONCLUSIONS}

The evaluation of the rate of absorption and chloride penetrability of concrete was performed in this research, according to ASTM C 1585 and ASTM C 1202, respectively. By incorporating fly ash and silica fume to substitute part of the cement is proven to increase the ability of concrete to resist the water and chloride penetrability. The finding of the current result shows that amount of cement substitution is affect the overall result of absorption and chloride penetrability. Furthermore, the addition of fly ash is the most effective way to enhance the rate of water absorption of the concrete. The substitution of cement with silica fume and a combination of fly ash and silica fume was proven not really effective in reducing the rate of water absorption. However, all type of concrete with supplementary material, including CFA, CSF and CSM, is confirmed to significantly improved the ability of concrete to resist chloride penetration compared with normal concrete (NC).

\section{ACKNOWLEDGEMENT}

The authors appreciate the financial support from Institut Teknologi Sepuluh Nopember (ITS)

\section{REFERENCES}

[1] D. Chen and S. Mahadevan, "Chloride-induced reinforcement corrosion and concrete cracking simulation," Cem. Concr. Compos., vol. 30, no. 3, pp. 227-238, Mar. 2008.

[2] Y. Zhao, J. Yu, Y. Wu, and W. Jin, "Critical thickness of rust layer at inner and out surface cracking of concrete cover in reinforced concrete structures," Corros. Sci., vol. 59, pp. 316-323, Jun. 2012.

[3] H. S. Wong, Y. X. Zhao, a. R. Karimi, N. R. Buenfeld, and W. L. Jin, "On the penetration of corrosion products from reinforcing steel into concrete due to chloride-induced corrosion," Corros. Sci., vol. 52, no. 7, pp. 2469-2480, Jul. 2010.

[4] K. Hong, "Cyclic Wetting and Drying and its Effects on Chloride Ingress in Concrete," University of Toronto, 1998.

[5] I. Zafar and T. Sugiyama, "The influence of bending crack on rebar corrosion in fly ash concrete subjected to different exposure conditions under static loading," Constr. Build. Mater., vol. 160, pp. 293-307, 2018.

[6] Y. Zhao, J. Yu, B. Hu, and W. Jin, "Crack shape and rust distribution in corrosion-induced cracking concrete," Corros. Sci., vol. 55, pp. 385-393, Feb. 2012. 
[7] K. Subbiah, S. Velu, S. Kwon, H. Lee, N. Rethinam, and D. Park, "Electrochimica Acta A novel in-situ corrosion monitoring electrode for reinforced concrete structures," Electrochim. Acta, vol. 259, pp. 1129 1144, 2018.

[8] S. P. Zhang and L. Zong, "Evaluation of relationship between water absorption and durability of concrete materials," Adv. Mater. Sci. Eng., vol. 2014, 2014.

[9] P. D. P. Kumar Mehta and P. D. Paulo J. M. Monteiro, Concrete: Microstructure, Properties, and Materials, Fourth Edition, 4th ed. New York: McGraw-Hill Education, 2014.

[10] P. S. Abdurahman Alhozaimy and Faiz Mirza, "Effects of Curing Conditions and Age on Chloride Permeability of Fly Ash Mortar," ACI Mater. J., vol. 93, no. 1,1996

[11] A. M. Diab, A. E. M. Abd Elmoaty, and A. A. Aly, "Long term study of mechanical properties, durability and environmental impact of limestone cement concrete," Alexandria Eng. J., vol. 55, no. 2, pp. 1465$1482,2016$.

[12] S. H. Alsayed and M. A. Amjad, "Strength, Water Absorption and Porosity of Concrete Incorporating Natural and Crushed Aggregate," J. King Saud Univ. Eng. Sci., vol. 8, no. 1, pp. 109-119, 1996.

[13] S. F. Korenkova and Y. V. Sidorenko, "Improving durability of cement composite materials," Procedia Eng., vol. 111, no. TFoCE, pp. 420-424, 2015.

[14] H. A. Mohamed, "Effect of fly ash and silica fume on compressive strength of self-compacting concrete under different curing conditions," Ain Shams Eng. J., vol. 2, no. 2, pp. 79-86, 2011.

[15] D. Wang, X. Zhou, Y. Meng, and Z. Chen, "Durability of concrete containing fly ash and silica fume against combined freezing-thawing and sulfate attack," Constr. Build. Mater., vol. 147, pp. 398-406, 2017.

[16] R. A. Wahab, M. N. Mazlee, S. B. Jamaludin, and K. N. Ismail, "Effects of fly ash addition on compressive strength and flexural strength of foamed cement composites," Adv. Mater. Res., vol. 795, no. May 2014, pp. 664-668, 2013.

[17] D. Nagrockienè and A. Rutkauskas, "The effect of fly ash additive on the resistance of concrete to alkali silica reaction," Constr. Build. Mater., vol. 201, pp. 599-609, 2019.

[18] H. Madani, M. N. Norouzifar, and J. Rostami, "The synergistic effect of pumice and silica fume on the durability and mechanical characteristics of ecofriendly concrete," Constr. Build. Mater., vol. 174, pp. 356-368, 2018.

[19] S. Chandra and K. Bendapudi, "Contribution of Fly ash to the properties of Mortar and Concrete," Int. J. Earth Sci. Eng., vol. 04, no. October 2011, pp. 1017-1023, 2015.

[20] V. Srivastava, V. . Agarwal, and R. Kumar, "Effect of Silica Fume on Mechanical Properties of Concrete Incorporating Steel Slag Powder," Wuhan Univ. J. Nat. Sci., vol. 24, no. 1, pp. 86-92, 2019. 